\title{
Erratum to "Global and regional ventilation during high flow nasal cannula in patients with hypoxia"
}

\author{
Dong Hyun Lee ${ }^{1}$, Eun Young Kim², Ga Jin Seo², Hee Jung Suh², Jin Won Huh², Sang-Bum Hong ${ }^{2}$, \\ Younsuck Koh², Chae-Man Lim² \\ ${ }^{1}$ Department of Pulmonology and Intensive Care Medicine, Dong-A University Hospital, Dong-A University College of Medicine, Busan; ${ }^{2}$ Department of \\ Pulmonary and Critical Care Medicine, Asan Medical Center, University of Ulsan College of Medicine, Seoul, Korea
}

In the article entitled "Global and regional ventilation during high flow nasal cannula in patients with hypoxia," the submission date of the revised version for the peer-review process was not stated. The submission date of the revised version is indicated in bold as follows.

Received on September 19, 2017;

Revised December 14, 2017;

Accepted on December 14, 2017

Copyright (C) 2021 The Korean Society of Critical Care Medicine

This is an Open Access article distributed under the terms of Creative Attributions Non-Commercial License (https:// creativecommons.org/li-censes/by-nc/4.0/ which permits unrestricted noncommercial use, distribution, and reproduction in any medium, provided the original work is properly cited. 